\title{
Openness and honesty when things go wrong: the professional duty of candour (GMC guideline)
}

\section{Hannah Jacob, ${ }^{1}$ Joseph Raine ${ }^{2}$} ${ }^{1}$ UCL Institute of Child Health,
London, UK
${ }^{2}$ Department of Paediatrics,
Whittington Hospital, London,
UK

\section{Correspondence to} Dr Joseph Raine, Department of Paediatrics, Whittington Hospital, Magdala Avenue, London N19 5NF, UK; joseph. raine@nhs.net

Received 1 November 2015 Revised 17 February 2016 Accepted 24 February 2016 Published Online First 21 March 2016

\section{CrossMark}

To cite: Jacob H, Raine J. Arch Dis Child Educ Pract Ed 2016;101:243-245.

\section{INFORMATION ABOUT CURRENT GUIDELINE}

In June 2015, the General Medical Council (GMC) and Nursing and Midwifery Council (NMC) jointly published the guidance Openness and honesty when things go wrong: the professional duty of candour. ${ }^{1}$ This guidance was developed in response to the Francis report about the Mid Staffordshire NHS Foundation Trust. ${ }^{2}$ It elaborates on the joint statement from eight regulators of healthcare professionals in the UK about the professional responsibility of all healthcare professionals to be honest with patients when things go wrong. ${ }^{3}$

The guidance builds on the principles set out by the GMC in Good Medical Practice and by the NMC in The Code: Professional Standards of Practice and Behaviour for Nurses and Midwives. ${ }^{4}{ }^{5}$ It is guidance for individuals meaning that even if you are not the person reporting adverse incidents and speaking to patients if things go wrong, you must make sure that someone in the team has taken responsibility for this and support them as needed.

This guidance applies to all doctors registered with the GMC across the UK. In addition, there is now a statutory duty of candour, meaning a legal obligation, for NHS organisations within England as well as independent health and social care providers. This follows the Health and Social Care Act, which came into force in November 2014. Different laws apply in other parts of the UK.

\section{WHEN DOES THE DUTY OF CANDOUR APPLY?}

The Francis report is explicit that any patient harmed by the provision of a healthcare service is informed of the fact and offered an appropriate remedy, regardless of whether a complaint has been made or a question asked about it. The statutory duty of candour applies when a patient has been subjected to moderate harm or worse, as a result of an error. Cases where an error has led to severe harm or death are usually clear cut. The definition of moderate harm requires a degree of professional judgement but according to the Care Quality Commission it includes harm that results in a longer hospital admission, an unplanned return to surgery or an unplanned readmission. ${ }^{6}$ Moderate harm is harm that is significant but not permanent.

The following is an example of severe harm in which the duty of candour applies. A 15-month-old presented to clinic with a limp and was found to have developmental dysplasia of the hip. The child's mother had developmental dysplasia of the hip and though the child's newborn examination was normal, the positive family history and the hospital's protocol meant that a hip ultrasound should have been performed. This was not arranged, the diagnosis was delayed and the child required surgery (box 1).

\section{KEY ISSUES ADDRESSED IN THIS GUIDELINE}

- Patients should be given clear, accurate information about any proposed treatment or care. This includes the risks of the proposed treatment and the risks of any alternative options.

- Patients should be told what has happened as soon as someone realises something has gone wrong with their care. It is not necessary to wait for the outcome of any investigations.

- Healthcare professionals should offer a personalised apology ('I am sorry...'). This does not mean that you are admitting legal liability for what has happened or that you are taking personal responsibility for 


\section{Box 1 Resources}

Full General Medical Council (GMC) guidance on the professional duty of candour http://www.gmc-uk.org/guidance/ethical_guidance/ 27233.asp

Good Medical Practice (GMC) http://www.gmc-uk.org/guidance/good_medical_ practice.asp

The professional duty of candour (joint statement) http://www.gmc-uk.org/Joint_statement_on_the professional_duty_of_candour_FINAL.pdf_58140142. pdf

GMC Hot Topics-duty of candour http://www.gmc-uk.org/guidance/27275.asp

Medical Defence Union guidance and case studies http://www.themdu.com/guidance-and-advice/guides/ statutory-duty-of-candour/statutory-duty-of-candour

Medical Protection Society guidance http://www.medicalprotection.org/uk/for-members/ general-practice/practice-xtra/cqc-inspections/ regulation-20-duty-of-candour

something that was not your fault (see box 2). Indeed, a GMC fitness to practise panel may view an apology as evidence of insight.

- Professional judgement should be used when considering whether to tell patients about a near miss (an adverse incident that had the potential to result in harm but did not do so). Any uncertainty about whether or not to tell a patient about a near miss should be discussed with a senior colleague.

\section{Box 2 Apologising to a patient}

An apology should include:

1. What happened.

2. What can be done to deal with any harm caused.

3. What will be done to prevent someone else being harmed.

You should give information:

- That the patient wants and needs in a form they can understand.

- In a place and at a time when they can best understand and retain the information.

- In a considerate way respecting their right to privacy and dignity.

- About who to contact in the healthcare team to ask further questions.

- About independent advocacy (eg, Patient Advice \& Liaison Service (PALS)), counselling or other support services that can offer practical advice and emotional support.
- Early reporting when something has gone wrong with patient care is important to ensure that lessons can be learnt quickly and that further harm is prevented. This includes reporting adverse drug reactions and adverse incidents involving medical devices as well as patient safety incidents (see table 1). Many such reporting systems include questions about the duty of candour to ensure that these obligations have been fulfilled and some provide letter templates to facilitate writing to patients and families.

\section{WHAT DO I NEED TO KNOW?}

\section{What should I stop doing?}

- Assuming someone else will talk to a patient and family when something has gone wrong.

- Discouraging colleagues from raising concerns about patient safety.

- Waiting until an investigation has been carried out to tell patients and their families about an error.

\section{What should I start doing?}

- Ensure that when you realise something has gone wrong and after doing what you can to put matters right, that you or someone from the healthcare team speaks to the patient and family as soon as possible. This should be documented in the medical notes and followed up with a letter to the patient and their family which includes a written apology.

- Share with the patient all you know and believe to be true about what went wrong, why and what the likely consequences are, both short and long term.

- Give the patient the opportunity to indicate if they do not want to be given every detail and make it clear to them that they can change their mind and have more information at any time.

Table 1 Examples of reporting systems and schemes in the UK

\begin{tabular}{|c|c|}
\hline Reporting system/scheme & Uses \\
\hline $\begin{array}{l}\text { National Reporting and Learning } \\
\text { System }\end{array}$ & $\begin{array}{l}\text { Adverse and patient safety incidents } \\
\text { in England and Wales-all } \\
\text { organisations upload their incidents } \\
\text { to this system }\end{array}$ \\
\hline
\end{tabular}

Yellow Card System (run by the Medicines and Healthcare products Regulatory Agency (MHRA) and Suspected adverse drug reactions in the Commission on Human Medicines)

MHRA the UK

Healthcare Improvement Scotland

Adverse incidents involving medical devices in the UK

Adverse incident management across the NHS in Scotland

Datix incident reporting system

Used by around $75 \%$ of NHS hospital trusts to report adverse incidents and near misses

National Patient Safety Alerting System (run by NHS England) 
Box 3 Additional duties for clinicians with

management responsibilities

Foster a culture of learning and improvement.

- Ensure systems are in place to give early warning about a possible failure in the clinical performance of individuals or teams, eg, appraisals, clinical audits, review of patient feedback and outcomes.

- Make sure your team is appropriately trained in patient safety, supported to openly report adverse incidents and that a system is in place for reporting incidents and handling complaints.

- Make sure that the systems in place allow learning from adverse incidents and near misses and change of practice where needed.

- Protect staff who raise concerns in good faith, so-called whistleblowers, from unfair criticism.

- Consider whether you should tell a patient about a near miss. This information may be something a patient would want to know and not telling them may damage their trust and confidence in you and the healthcare team.

- Recognise that you have a responsibility to set an example and encourage openness and honesty within your team. You must be open with your colleagues and employers, taking part in investigations where requested. Additional duties of senior clinicians are outlined in box 3 .

- Discuss adverse incidents, near misses and complaints at your appraisal.

\section{What can I continue to do as before?}

- Apologise when something has gone wrong. This should be a personalised apology rather than a general expression of regret on the organisation's behalf (see box 2). The guidance on the duty of candour from the GMC identifies the professional standard against which a doctor would be judged in any fitness to practise hearing.

- Ensure you record the details of any apology in the patient's medical notes.

\section{Box 4 Summary of key points}

- All healthcare professionals have a duty to tell patients when something has gone wrong with their treatment or care.

- It is important to offer a personalised apology, offer an appropriate plan for putting matters right (if possible) and explain the short-term and long-term effects of what has happened.

- Healthcare professionals must support each other in being open and honest and not stop someone from reporting concerns.

- Healthcare professionals must contribute to reporting systems and schemes locally and nationally for reporting adverse incidents and near misses.
- Respond honestly to patients' questions and explain anything that is uncertain.

- Tell patients about risks that occur often, those that are serious and those that the patient is likely to think are important when outlining treatment options.

- Talk to families if something has gone wrong that has caused a patient's death or moderate or severe harm. (There may be some very rare exceptions to this. For example, in the case of a Fraser competent teenager in whom there have been complications following a termination of pregnancy).

- Report errors and adverse incidents through the reporting system in your organisation as well as to national schemes where appropriate (see table 1). This should be done as soon as possible and certainly within 7 days.

- Participate in reviews and audits of the standards and performance of any team you work in and take steps to resolve any problems.

- Raise your concerns about patient safety initially within your organisation where possible. This may be with your manager, the consultant in charge of the team or the medical director. For doctors in training, it may be appropriate to raise concerns with the Deanery in Northern Ireland, Wales and Scotland or your Local Education and Training Board (LETB) in England.

- Raise concerns if your organisation does not support staff to report adverse incidents or does not have a system in place to do so (box 4).

Acknowledgements Thank you to Liz Bennett for her comments and guidance.

Contributors $\mathrm{HJ}$ drafted the initial manuscript. JR provided expert opinion on the initial draft. Both authors have approved the final version.

Funding $\mathrm{HJ}$ is an Academic Clinical Fellow funded by the National Institute for Health Research.

Competing interests None declared.

Provenance and peer review Commissioned; externally peer reviewed.

\section{REFERENCES}

1 General Medical Council and Nursing and Midwifery Council. Openness and honesty when things go wrong: the professional duty of candour. London: General Medical Council and Nursing \& Midwifery Council, 2015.

2 Francis R. Report of the Mid Staffordshire NHS Foundation Trust Public Inquiry. London: The Stationery Office, 2013.

3 General Chiropractic Council, General Dental Council, General Medical Council, General Optical Council, General Osteopathic Council, General Pharmaceutical Council, Nursing and Midwifery Council, Pharmaceutical Society of Northern Ireland. The professional duty of candour. 2014.

4 General Medical Council. Good Medical Practice. London: GMC, 2013.

5 Nursing and Midwifery Council. The code: professional standards of practice and behaviour for nurses and midwives. London: NMC, 2015.

6 Care Quality Commission. Regulation 20: Duty of Candour. Information for all providers: NHS bodies, adult social care, primary medical and dental care, and independent healthcare. Newcastle, UK: Care Quality Commission, 2015. 